\title{
Pre-hospital diagnosis for stroke and trauma patients using microwave technology
}

\author{
Stefan Candefjord ${ }^{1,2^{*}}$, Mikael Persson ${ }^{1,2}$, Andreas Fhager $^{1,2}$, Bengt Arne Sjöqvist ${ }^{1,2}$, Jan-Erik Karlsson ${ }^{3}$, Mikael Elamm \\ From London Trauma Conference 2014 \\ London, UK. 9-12 December 2014
}

\begin{abstract}
Background
For stroke and traumatic brain injury (TBI) patients minimizing the time from stroke onset/accident to treatment is fundamental to increase the chances of achieving good clinical outcome. For patients with ischemic stroke thrombolytic treatment may be effective, but only $1-8 \%$ receive this treatment due to delays in seeking medical attention and late diagnosis. TBI patients with severe injury require immediate transportation to a trauma center. Microwave technology (MWT) has potential to be used for prehospital diagnosis of stroke and TBI patients by detecting intracranial bleedings and thereby make prehospital thrombolysis for stroke patients possible and increase triage accuracy for TBI patients.
\end{abstract}

\section{Methods}

Two clinical trials enrolling $20+25$ stroke patients performed with research prototype systems (Brain Alfa and Stroke finderR10, Medfield Diagnostics AB, Göteborg, Sweden) have been completed. Two further studies are ongoing.

Regarding TBI laboratory experiments using a human cranium phantom and numerical simulations of subdural hematoma (SDH) have been performed. The first clinical study assessing the potential for MWT to detect SDH has recently started.

The microwave-based systems use 8-12 transmitting and receiving antennas. The classification algorithm is trained on measurements on patients with confirmed diagnosis, using a leave-one-out procedure.

\section{Results}

For the clinical studies on stroke patients all cases of hemorrhagic stroke could be detected while correctly

\footnotetext{
* Correspondence: stefan.candefjord@chalmers.se

${ }^{1}$ Chalmers University of Technology, Göteborg, Sweden

Full list of author information is available at the end of the article
}

classifying most cases of ischemic stroke [1]. For the SDH models the total classification accuracy was $98-100 \%$, and SDH of different sizes and at different positions could be distinguished.

\section{Conclusions}

MWT has potential to improve the acute care for stroke and trauma patients by making a prehospital diagnosis. This would lead to decreased human suffering and large societal economic savings.

\section{Authors' details}

${ }^{1}$ Chalmers University of Technology, Göteborg, Sweden. ${ }^{2}$ MedTech West, Göteborg, Sweden. ${ }^{3}$ Sahlgrenska University Hospital, Göteborg, Sweden.

\section{Published: 11 September 2015}

Reference

1. Persson $M$, et al: Microwave-based stroke diagnosis making global prehospital thrombolytic treatment possible. IEEE Trans Biomed Eng 2014, 61:2806-2817.

doi:10.1186/1757-7241-23-S2-A26

Cite this article as: Candefjord et al:: Pre-hospital diagnosis for stroke and trauma patients using microwave technology. Scandinavian Journal of Trauma, Resuscitation and Emergency Medicine 2015 23(Suppl 2):A26.

Submit your next manuscript to BioMed Central and take full advantage of:

- Convenient online submission

- Thorough peer review

- No space constraints or color figure charges

- Immediate publication on acceptance

- Inclusion in PubMed, CAS, Scopus and Google Scholar

- Research which is freely available for redistribution 